\title{
MRS: Carrying the Materials Message Up the Hill
}

U.S. government support for the physical science research enterprise, including materials science and engineering, is dependent on continual nurturing and advocacy. The immediate and pressing need to state and restate our case has been emphasized in this space and in many other science-oriented media. Outreach to Washington has been a major theme of the current Materials Research Society leadership and of several recent MRS presidencies.

This past summer, the MRS Board of Directors took the unprecedented step of holding its summer meeting in Washington, D.C. In addition to covering the regular Society business that arises at this time of year, we devoted a full day to an extensive program of 27 congressional office visits as well as a meeting with officials at the State Department. A large majority of board members, MRS staff directors, and selected delegates of the MRS Government Affairs Committee participated under the leadership and guidance of our Washington consultant. This was by far the largest single-day advocacy effort in MRS history. Many valuable contacts were made, and important information was gleaned on how to leverage our resources for future advocacy.

A few of us had some previous congressional visit experience from which to draw, either from our day jobs, multisociety visit days, or previous experience working with our consultant. Many others were complete novices going into the activity, but quickly caught onto the routine and the methods for effectively conveying the most beneficial and persuasive points. It quickly became apparent that each visit would be unique. Some representatives and senators are already so committed to science and employ such knowledgeable staffers (including our own Congressional Fellows!) that we end up learning from them. Other legislators are extremely skeptical and need to be walked through the reasons why science and engineering might matter to them or their constituents.

It is not necessarily the case that the visits to "friendly" offices are the most productive or enjoyable. In one ostensibly friendly office, rather than being admired for being science supporters, we were implicitly criticized for not having done

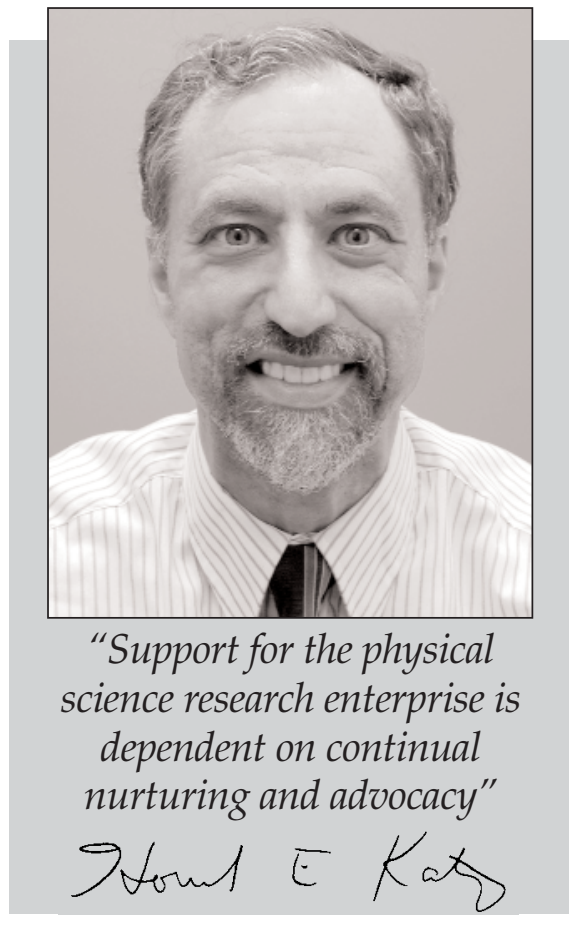

enough to oppose the tax cuts that have contributed to the current funding crunch. Another allied office would only accept numerical evidence to present to the legislator, while still another seemed interested only in the "people side" of issues.

In contrast, some of the initially resistant offices offered opportunities to advance our case. For example, the office of one particular appropriator was receptive to discussion about the importance of the National Science Foundation in seeding technologies that offer his low-tech, declining industries a viable chance at reinvention and staving off further layoffs.

We discovered the occasional personal touch that helped connect with scientifically uninitiated staffers. One of our delegates spoke of having bested Reggie Jackson, the Hall of Fame baseball player, in a Philadelphia youth league, making quite an impression on a Philadelphia staffer. Another was able to reach a staffer through a discussion of the Spider Man movies in which overtones concerning nuclear fusion and nanotechnology could be found. Mentioning large in-state facilities such as land grant universities and national laboratories was generally effective, especially when done by a home district employee or graduate. Everyone likes to be associated with winners, and emphasizing how we are developing the "best" students and the "most competitive" technologies resonated.

It also helped to recognize how legislators prefer to package issues. Science funding is really a "jobs and startups" issue, and the need to ease the student and collaborator visa application process is actually a national security issue. This last point was driven home during our meeting with the State Department, where it became clear that offering a military/economic security benefit to lessening restrictions on international visitors is essential to counteracting the perceived risk of "loosening" our frontiers.

We came away from our experience with several elements for incorporation into our future strategies. We have already learned the benefits of combining efforts with other science societies and institutions. We must also search for allies outside the traditional science community, such as in business roundtables and charitable foundations that already enjoy warm relationships with Congress. We need to build bridges to the executive branch, and spread our visits over the entire budget calendar. We can leverage the MRS Strange Matter traveling science exhibition in the districts where the exhibition is being hosted by inviting local officials to the venue.

To expand outreach efforts beyond that of the MRS leadership, we are launching an MRS-wide follow-through and continuing advocacy endeavor in the form of a Web-based congressional letter-writing feature called Materials Voice (www.mrs. $\mathrm{org} / \mathrm{pa} /$ materialsvoice). Under the persistent and dedicated leadership of the MRS Government Affairs Committee, this software will debut at the 2004 MRS Fall Meeting and is described elsewhere in this issue of MRS Bulletin. Through this and other outreach efforts, we aim to involve the entire MRS membership in the engagement of U.S. government support for our mission: to advance interdisciplinary materials research to improve the quality of life.

HOWARD E. KATZ 2004 MRS President

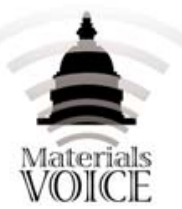

